\title{
Stimulating niche nurturing process for heat production with nuclear plants in France: A multi-level perspective
}

\author{
Martin Leurent ${ }^{1,2, *}$ \\ ${ }^{1}$ Itésé, CEA, Université Paris-Saclay, 91191 Gif-sur-Yvette, France \\ 2 Laboratoire Génie Industriel, CentraleSupélec, Université Paris-Saclay, Grande Voie des Vignes, 92290 Chatenay-Malabry, \\ France
}

Received: 28 May 2018 / Received in final form: 18 December 2018 / Accepted: 7 January 2019

\begin{abstract}
This paper examines how intermediaries could interact with other important actors identified by the multi-level perspective (MLP) framework, the niche actors and regime actors, to create niches for nuclear heat production in France. Whatever is the source, recovering the wasted heat is a matter of energy efficiency. Nuclear plants could remain used for several decades in France. It is thus legitimate to investigate those possible niche nurturing processes which may allow a more efficient use of this technology. Challenges are high, and our conclusions modest regarding the possible breaking through of such exploratory and collective systems. Without significant windows of opportunity, even the most willing intermediation may not be able to change the status quo. It is however important to highlight the multifarious pathways that energy transitions could follow. Drawing on lessons from the MLP, this paper proposes three key actions for intermediation willing to move beyond technology-push approaches that can lead to tension and low legitimacy. These are, sharing questions instead of knowledge; mobilise, interest, involve a legitimate place; and prevent or avoid conflicts among stakeholders. Regime changes possibly enhancing the deployment of sustainable heating systems, not only nuclear plant sourced, are also discussed.
\end{abstract}

\section{Introduction}

In those countries which are using nuclear energy for power production, the commercial production of heat with nuclear plants generates a growing interest (see e.g. [1-5]). Towards 2025-2030, the French nuclear capacity should remain significant $\left(40-63 \mathrm{MW}_{\mathrm{e}}\right)$. This despite plans to reduce the share of nuclear production in the electricity mix from $75 \%$ (2016 level) to $50 \%$ (2025), as targeted by public authorities [6]. In the longer term, dispatchable power plants may present some new benefit to balance power systems with large amounts of intermittent renewables $[7,8]$. Given the path dependence approach (past investments made), as well as the low carbon profile of this energy source, nuclear plants could remain in use for a number of decades in France. Some of these plants could be optimised to supply heat to nearby industrial sites or district heating (DH) networks. This would favour energy efficiency and decarbonisation of the heat sector while reducing the use of imported fossil-fuels. The cost and climate savings

\footnotetext{
* e-mail: martin.leurent@tractebel.engie.com
}

potential of DH production with nuclear plants have been explored for the Parisian, Lyon and Dunkirk metropolitan areas [9-12]. Leurent [13] has studied the feasibility of supplying $250^{\circ} \mathrm{C}$ steam to industrial sinks, currently mostly using on-site fossil-fuels boilers, and found suitable locations for cost-effective implementation. Leurent et al. [14] however emphasized the importance of social, political, institutional and psychological challenges these projects can face.

In the case of France, it is legitimate to explore how a niche for the implementation of first projects could be created. Caution is however required when addressing such a controversial debate. One could be tempted to adopt a technology push approach, focusing on the accumulation of facts and data and considering consumers with given needs and preferences, with the aim to demonstrate the intrinsic value of the system. The logic underlying local decisionmaking processes is however far from being purely rational, but is rather derived from improvised economic, social and political principles, varying widely from a context to another [15,16]. An excessively narrow technology push approach (through top-down policies) can lead to unintended consequences of network tensions, low legitimacy and credibility, due to the fact that it neglects the 
importance of improvisation and shared learning $[17,18]$. This is particularly true for energy projects in liberalized economy such as France [19].

The above discussion calls for theoretical approaches specifically designed to analyse the emergence of innovative energy systems involving disconnected stakeholders and complex, real-world phenomenon. To that purpose, this article adopts a multi-level perspective (MLP) approach. The research scope is detailed in Section 2. Section 3 explores and discusses actions that could stimulate the experimentation of nuclear heat production in France. The paper ends with the discussion and conclusion.

\section{Research scope}

Section 2.1 first presents the MLP framework. Section 2.2 then discusses the specificity of MLP approaches addressing collective and exploratory systems such as heat production with nuclear plants in France.

\subsection{Multi-level Perspective (MLP)}

The MLP analyses development strategies that participate in transforming the cultural, institutional, social, political, market, industry, infrastructure, technology and science subsystems of society that are locked-in and characterize the dominant socio-technical regime [20,21]. The MLP "distinguishes between three analytical levels with increasing temporal stability: niche (flexible and fluid), regime (semi-stable) and landscape (slow societal processes that provide the context for regime stability or change)" [22]. Kivimaa and Kern [23] explain that "transitions come about through interactions between landscape (e.g. macroeconomic and macro-political trends, significant environmental changes and demographic trends), regime (e.g. the deep structure of the socio-technical system involving alignment between technologies, infrastructure, institutions, practices, behavioural patterns, markets, industry structures, etc.) and niches (spaces where various technical, social and organisational innovations are created and tested)" (p. 206).

Employing the MLP in practice consists in exploring strategies and pathways for how change and persistence can occur in the same system $[24,25]$. The revolt process, that is, the drive for change from niches to encourage regime change, and the remember process, in which the regime characteristics demonstrate resilience to guide subsystem change [26]. Transitions (through revolt and remember processes) are often based on the negotiation of different stakeholders within a policy arena [27]. In this way, change in socio-technical systems is dependent on functions performed by actors at various points in time. The MLP can help to understand how individual or organizational actions can affect system change by stimulating the revolt process and/or secure the remember process [27]. The challenge is to capitalize on external pressures on the landscape during windows of opportunity to allow niche experiments to scale-up and change the regime [28]. The key actors of the MLP framework are the technology entrepreneurs (niche actors), the policy entrepreneurs (regime actors) and the intermediaries. The roles played by these actors in the development of innovative systems are depicted in Figure 1 and explicated here below:

- Technology entrepreneurs are niche actors that "focus on knowledge development and diffusion, articulation of visions, entrepreneurial activities, market formation, guidance of search activities, mobilization of resources, creation of legitimacy and overcoming of resistance to change" ([22], p. 13). These actors can be public or private utilities with the technical and financial ability to commercialize technologies. Technology entrepreneurs can lead "inclusive, practice-based and challenge-led initiatives designed to promote system innovation through social learning under conditions of uncertainty" [29]. They are however rarely willing to invest in innovative systems perceived as risky, challenging deeply rooted regimes boundaries, norms or routines.

- Policy entrepreneurs are regime actors that are "supporters of transition by forming powerful coalitions to push through a reform agenda that fits incumbent regimes interest, or opponents of transition by downplaying the need for transformation" ([22], p. 13). These actors can be political parties, national, regional or local authorities. They can have direct impacts on policy creation by linking a problem with solutions, and indirect impacts by changing the ideas flowing within the policymaking context [30,31]. Key roles played by policy entrepreneurs include "raising issue awareness, reclassifying existing conditions into something more politically appealing, framing the problem and potential solutions, and working to align the problem, solution and political streams during windows of opportunity" [32]. Policy entrepreneurs as regime actors have a set of skills that help identify opportunities for making institutional changes. These skills, when coordinated with the help of innovation intermediaries, can be critical for changing conditions to allow niche nurturing processes.

- Intermediaries are actors connecting the niche and regime levels via organizational and institutional networks within and between clusters. They "provide and distribute necessary information, services, mediation, and diffuse new technologies and practices" ([22], p. 14). The importance of intermediaries in innovation as change agents for coordinating niche and regime actions has been growing with the increased technological complexity and global competition [33,34]. These actors can be individuals or a group of people within organisations that include from public research bodies to trade associations, non-governmental organisations (NGO) or labour unions [35]. Universities can also participate to intermediation activities [36,37]. MLP case studies revealed that public sector actors deliver most of the intermediary functions, but private sector actors also played intermediary roles for supporting learning processes (see e.g. [38-40]). Intermediation is sometimes done by consultants, although national government funding is often needed to enable their involvement at the local level (see [41]; analysing DH development in the United Kingdom). 


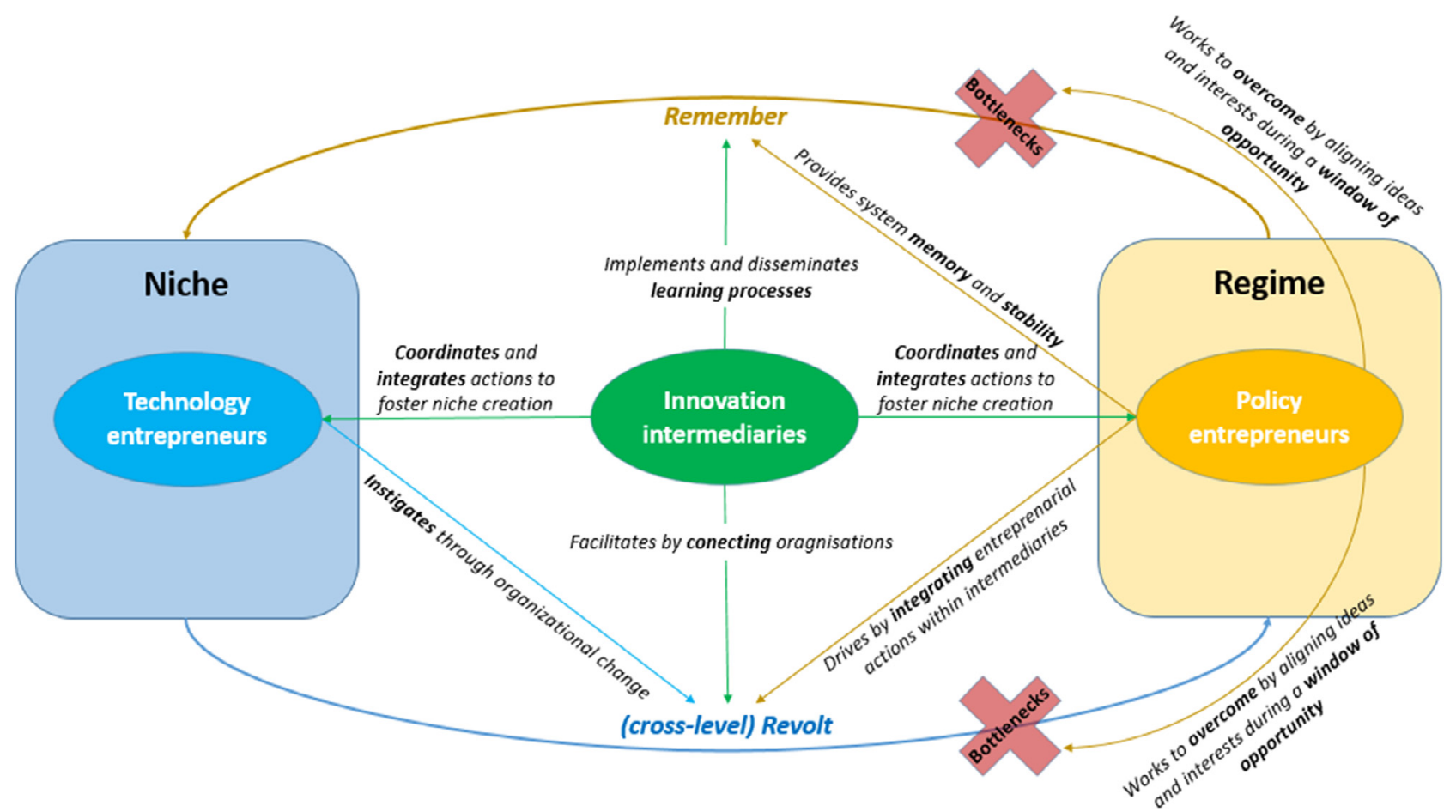

Figure 1. MLP framework for the development of innovative systems: Intermediaries as agents for stimulating transitions. Notes: the research question of this paper (shown in Sect. 2.3) focuses on the revolt process. Future research could further investigate the remember process.

Critiques of the MLP include the fact that it does not incorporate political or democratic processes, but rather, brings selected actors together to build consensus on a longterm strategic plan as part of a transition arena [42]. Furthermore, the MLP does not make power, conflict and decision-making 'visible and contestable' as it treats the political landscape as neutral [42]. Gliedt et al. [32] as well as [43] however outline how, precisely because it considers the political landscape as neutral, the MLP is advantageous and offers direction to local and regional actors in creating green economic development as a politically feasible strategy during times of institutional uncertainty.

\subsection{MLP addressing exploratory and collective innovations}

There is a significant difference between being an intermediary in cases where problems are clearly known, actors are known and there is a consensus in the potential of the technology (most likely to result in more incremental innovations), and cases where the problems are ill-defined and neither the role nor interest of actors is given (exploratory innovations). Research has emphasised that intermediaries face increasing difficulties in addressing the second type of innovation [44]. Their activities get more diverse and more complex, which implies that their role becomes unclear and sometimes problematic [45]. While there are at least 50 commercial experiences of nuclear heat production [14,46], none is located in France, explaining why many French actors consider such systems as exploratory. Besides, it is a collective innovation in the sense that it would require close collaboration between diverse and disconnected stakeholders (e.g. nuclear plant operator, distribution system operator, end-user(s)), and this is (40-60 yr minimum; see [10]).

In exploratory and collective innovations, the connection role of intermediaries is all the more complicated because the relevant stakeholders are not always identified ex ante and successful intermediation requires ongoing multilateral exchange to be adopted within the network $[47,48]$. Based on the MLP literature, I identified three core functions that must be fulfilled by those intermediaries which are willing to stimulate niche creation for collective and exploratory innovations:

- Stimulate innovative approaches: the challenge is to arouse the interest of a wide variety of actors by developing and offering favourable conditions for questioning, learning and experimenting.

- Involve, commit and mobilize: technology and policy entrepreneurs as well as the potential end-user(s) must be convinced and mobilised. Convincing is a matter of framing a common issue that is considered a problem by potential actors in the innovation system. Sufficient exogenous incentives (e.g. market growth potential, economic factors, pressure for climate change mitigation) are required but can be complemented by resource mobilisation (e.g., competence and human capital, financial capital and complementary assets) in order to create and maintain a network for multilateral exchanges [49]. The intermediary can facilitate the formation of an 
Table 1. Actors that could be involved in the revolt and remember processes surrounding the development of heat production with nuclear plants in France.

\begin{tabular}{|c|c|c|}
\hline Technology entrepreneurs & Innovation intermediaries & Policy entrepreneurs \\
\hline Dalkia & ADEME & European Commission \\
\hline $\mathrm{EDF}$ & AMORCE & $\begin{array}{l}\text { Local authority \& clusters } \\
\text { (e.g. Metropole de Strasbourg) }\end{array}$ \\
\hline Engie/Cofely & ANCRE & National authorities \\
\hline $\begin{array}{l}\text { Factory owners (e.g. Arkema, } \\
\text { Bonduelle, Renault) }\end{array}$ & CEA & Regional authority \& clusters \\
\hline Idex & $\begin{array}{l}\text { Consultants (e.g. Apave, } \\
\text { Bureau veritas) }\end{array}$ & Political parties \\
\hline \multirow{8}{*}{$\begin{array}{l}\text { Other equipment suppliers } \\
\text { (e.g. Adionics, Idhelio, Inpal, Ryb, } \\
\text { Trianon échangeurs) }\end{array}$} & Euroheat\&Power & \\
\hline & IAEA & \\
\hline & Fedene & \\
\hline & FNCCR & \\
\hline & NEA/OECD & \\
\hline & NGO (e.g. CLCV, MNLE, OREE) & \\
\hline & $\mathrm{SNCU}$ & \\
\hline & $\begin{array}{l}\text { Universities \& other research organisations } \\
\text { (e.g. BRGM, CNRS, Locie) }\end{array}$ & \\
\hline
\end{tabular}

"advocacy coalition", which places new objectives on the agenda and creates "legitimacy for a new technological trajectory" ([50], p. 425).

- Prevent or avoid conflicts: the need for collaboration clearly implies a necessity to avoid sources of conflicts [51]. The introduction of new technologies or systems often implies a need for change, to which established market actors often resist [25]. Overcoming such resistance to change often requires the introduction of innovative business models that unlocks the technology for deployment [19].

These key functions represent a useful analytical framework to explore possible niche nurturing processes in collective and exploratory innovations. Activities at the beginning of the process serve to raise interest and questioning key actors on issues not directly in their core business. It is then needed to convince key actors of the value of the innovation and potential benefits that could be realized. Preventing possible split incentives or conflicts is also required to limit the tensions that can arise from early discussions.

\subsection{Research questions}

This paper aims to examine how innovation intermediaries could interact with other important actors identified by the MLP, the niche actors and regime actors, to create niches for nuclear heat production in France. As normative questioning involves normative answers, subjective judgements are inevitably included in the analysis. Normative questioning is however necessary to generate new ideas on systems which have not yet been experienced in a particular context.

\section{An intermediary driven niche nurturing process}

Section 3 aims to answer the research question regarding the role of intermediaries in stimulating experimentation of collective systems using heat from French nuclear plants. In order to provide further insights to policy makers and stakeholders, Table 1 shows the names of organisations that can be categorized as technology, policy entrepreneurs and innovation intermediaries in the case here studied. Table 2 then provides a summary of the actions that French intermediaries could lead, which are further discussed in Sections 3.1, 3.2 and 3.3.

\subsection{Sharing an agenda of open issues instead of sharing knowledge}

Because of the organizational complexity that collective and exploratory innovation fosters, one risk is to engage in the process as if it is already known which alternative is the best and which stakeholders are relevant. Schot and Geels [18] note that in many technology experimental projects, networks have tended to be too narrow, following technology push approaches (accumulation and dissemination of facts and data). When stakeholders have 
Table 2. Actions that could be led by intermediaries to nurture niche experiment.

Sharing an agenda of open issues instead of sharing knowledge (Sect. 3.1)

Introducing open questions on the topic of interest and providing permanent domains for the exchange of ideas

Organization of events, meetings or novel forum bringing together a large panel of participants likely to have different perspectives and experiences

Drawing (locally) new knowledge from participants
Mobilise, interest, involve a legitimate place (Sect. 3.2)

Finding funding sources

to support activities

Organize cross-sector

workshops on a regular

basis and over several years
Prevent or avoid conflicts (Sect. 3.3)

Identification and challenging of institutionalized practices that obstruct new practices

Introduction of new actor configurations (e.g. Mankala energy cluster; see Sect. 3.3.2) different, deeply rooted, perceptions of the pros and cons of energy alternatives, knowledge sharing activities can be seen as subjective, lobbyist discourses [14]. This is because legitimacy is based not on the knowledge itself but on the working conditions surrounding knowledge creation [52]. Sharing questions and unsolved problems can paradoxally be more efficient in the building-up of trust as it can help avoiding fixations [53]. Sharing open questions however requires to recognise that the issue at stake goes beyond the expertise of the stakeholders and requires a real explorative approach. This is not easy in itself, as overconfidence in what is currently known sometimes prevent actors from realizing how much is actually unknown [47].

When addressing collective and exploratory innovation, intermediaries should first focus on the organization of events, meetings or novel forum (possibly online e.g. webinar) bringing together a large panel of participants likely to have different perspectives and experiences (niche and regime actors but also other intermediaries; see Tab. 1). The identification of both the knowledge to acquire and the stakeholders to involve should be outputs and not input of these preliminary discussions. Intermediaries must not raise expectations regarding the solution but raise expectations regarding the capacity to generate multiple solutions. Discussions should go from general to narrow topics, possibly following an incremental set of open questions as proposed below:

(1) Which transition pathway should be prioritized to decarbonize the French heating sector?

(2) Which technology or system can be considered as innovative to that purpose?

(3) Do you think that collective system such as ecoindustrial parks are a good way of decarbonizing the industrial heat sector? If not, why? Do you see any obstacles to their experimentation and generalization?

(4) How to enhance systemic thinking habits considering the building envelop and the heating infrastructure as a whole instead of separate systems? Would it help accelerating the transition towards sustainable energy systems?
(5) What are the main challenges faced by the recovery of the waste heat from factories and thermal plants in France? Could they be overcome? How?

(6) Would it make any difference if the heat supplier were a nuclear plant? Why?

This preliminary stage can be primordial in order to build-up trust among actors. Besides, the financial investment is limited, especially if sharing online questionnaires or organizing webinar. The importance is the regularity and the framing of the initiative, not the form it takes. Providing permanent domains for the exchange of ideas, the intermediary work may influence the direction of transition through the change in the cognitive rules of the stakeholders [54]. Involving the regime actors is important as it enable a deeper institutional embedding of the new questioning. Intermediaries should however be aware that the outputs of such open discussions can result in unexpected ideas. It would anyway allow the collection of valuable materials (e.g. perceptions, goals, fixations and split incentives) which can serve to frame the future actions of intermediaries, that is, mobilise, interest and involve a legitimate place.

\subsection{Mobilise, interest, involve a legitimate place}

Research has highlighted that the building-up of trust is a key success factor in exploratory intermediation [53]. The building up of trust is however a complex and often illunderstood process. Tensions between neutrality and advocacy of local intermediation has been an obstacle to the implementation of several energy projects $[55,56]$. An intermediary may need to be perceived of as neutral in order to be regarded as a reliable and legitimate to a critical range of stakeholders. Complex intermediation combining public (local government agency, research institution) and private (environmental consultancy) organisations may be helpful in avoiding committed stance, either real or supposed $[34,57]$. 
This may be even more critical when considering nuclear heat production in France, since suspicion of 'nuclear-biased judgement' is common place in this country. Intermediary actions should be co-organized by 'non-nuclear actors' (ADEME, AMORCE, FEDENE, OREE, DH utilities, factory owners) and 'nuclear actors' (CEA, NEA, IAEA, EDF), and this from early stages. Integrating NGO to the cluster could provide unexpected insights and thus should be encouraged. Gathering these actors together to set up common actions and build shared visions would be a great asset to legitimate the place of nuclear heat production in national energy transition debates. It however requires overcoming organizational routines and creating of new business relationships. Preliminary discussions proposed in Section 3.1 could be a first step towards the establishment of regular, crosssectors working groups aiming to further explore the potential of nuclear heat production in France. Intermediaries would however need to mobilize significant resources (e.g. competence and human capital, financial capital and complementary assets) in order to make a success of these workshops, mobilizing a wide variety of actors over several years. In practice, the objectives of the working groups would be defined based on preliminary, open discussions (see Sect. 3.1). Two key activities can nonetheless be suggested:

- Collective knowledge and experience from elsewhere: despite being hardly measurable, behavioral or psychological means such as "resistance to change" inhibit the will of investing in projects perceived as exploratory or risky. Case studies are an important tool for increasing confidence in exploratory innovations [41]. While there are at least 50 experiences of commercial heat production with nuclear plants, only a few case studies are providing feedbacks discussing social, political or psychological dimensions (see [14,58]). There is a real need to lead additional case studies, interviewing those nuclear operators, distribution system operator, factory owners, and more importantly - local authorities, citizens, NGO which have experienced nuclear heat supply. Despite being different from the EC context, gathering views from the ongoing Chinese projects [59] would also be an asset.

- Identifying possible experimental projects in France: real experimentation of nuclear heat production in France should be seriously discussed among participants. This is however a complex topic which must be addressed carefully and preferably when people have learnt to know each other and accepted to play this 'exploratory game'. Leurent et al. [60] suggest that small-scale projects targeting the supply of heat to an industrial sink are the most likely to break through. This is because small-scale projects are less subject to split incentives among stakeholders and to unexpected technical problems, over costs and delays [61]. Besides, supplying an industrial customer may rise less opposition in comparison of providing district heat to an urban area.

If an experimental project is retained, caution is needed on how the objectives are then communicated and interpreted. The French Thermos nuclear DH project (1975-1981) allows drawing useful lessons to that respect.
According to [62], the Thermos project initially aimed to generate clear economic benefits. During the decisionmaking process, however, opponents succeeded in disseminating the idea than Thermos would not be competitive relative to traditional coal fired heat-only boilers. As a result, proponents change their strategies arguing that Thermos must be seen as a demonstration project opening the path for future, more economical, projects of that kind. Dalmasso [62] showed that this change of discourse has participated in reducing the legitimacy of the project, which ultimately led the local authority to nuance and then withdraw its support. It therefore follows that, if the expected economic benefits of a project are not large enough, the implementation would be difficult due to the fact that opponents would always be able to contest the technical-economic rationality.

Under the current (2015) spatial configuration, transporting $250^{\circ} \mathrm{C}$ steam from Le Bugey nuclear plant to the two chemical plants situated $1.8 \mathrm{~km}$ away could be an option [60]. The Gravelines nuclear site, with a pharmaceutical plant located $0.5 \mathrm{~km}$ away from the thermal plant, is also relevant. If not already invited, the factory owners as well as the concerned local authorities would now be at the heart of the discussions. The power plant could serve as the key organisation around which discussions are organised. A broad sense that the project is supported by national and local authorities would be required. Actions aiming to limit or share the risks (both financial and media) should be openly discussed (see Sect. 3.3). A pre-requisite to such discussions is the building-up of trust, which is a challenge by itself (see Sect. 3.1).

\subsection{Prevent or avoid conflicts}

Discussing business models and contractual arrangement from early stages is important since the perception of opposing interests may strongly penalized the establishment of an open and constructive dialogue [14]. Based on previous work from [14,63], two archetypal kind of actor configuration for nuclear heat production in France are discussed in Sections 3.3.1 and 3.3.2, namely nonintegrated clusters and Mankala cluster, respectively.

\subsubsection{Non-integrated cluster}

The organization chart of a non-integrated energy cluster is shown in Figure 2. This is the less challenging form of market configuration considering the current business models and governance structure of French actors. EDF would own and operate the nuclear plant, selling electricity to the external grid. Alongside, EDF would sell the heat to the distribution system owner and operator. The distribution system includes the pipelines and other equipments required to transport the heat from the thermal plant to the end-user (for technical aspects, see [64] or $[10,11,60]$ ). The heat would finally be sold to the end-user.

The advantages of non-integrated clusters are the limited alteration of existing regime boundaries, business models and routines; and the limited financial risk borne by the nuclear plant owner and operator. The inconvenients are: 


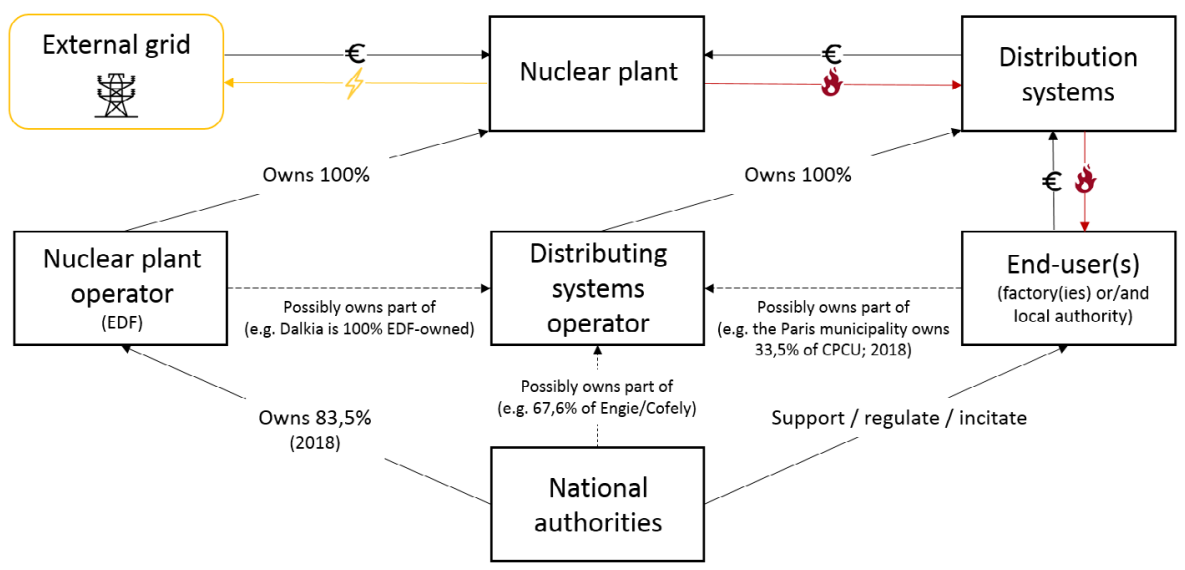

Figure 2. Organisation chart of a non-integrated energy cluster.

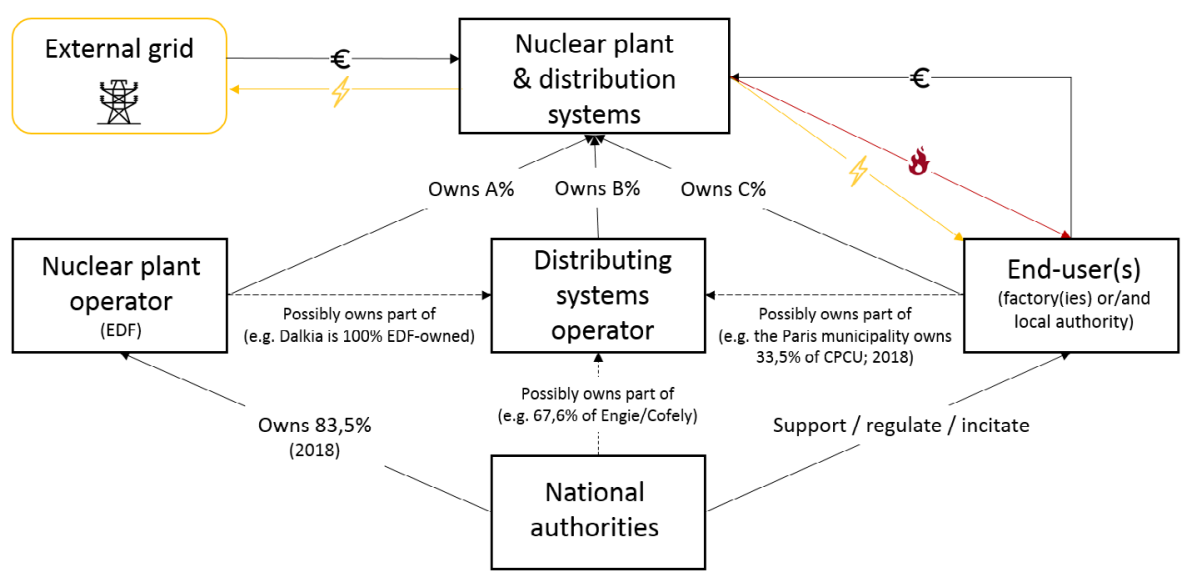

Figure 3. Organisation chart of a Mankala energy cluster.

- High financial risk for the distributing system operator and owner: this may inhibit its willingness to commit in such a long term, capitalistic project.

- Limited control of the end-user(s) on decision-making processes (e.g. pricing, energy flows management): this may lead to a lack of trust from the media and civil society. The end-user(s) would need important and trustworthy guarantee (possibly with financial penalty in case of non-respect) that the heat will be supplied whenever needed, without unplanned disruptions (especially important when supplying continuous industrial processes; see $[60,65])$.

- Possible conflict of interests: in the case of DH networks mostly. The Loviisa 3 project emphasized the competition that may exist between a new heat supplier (here the nuclear plant owner and operator) and the heat suppliers already in place [14]. The company owning and operating the DH network prior to the connection to the nuclear plant may perceive the introduction of a new player in the heat market as a potential threat for its market share and control. If the project aims to replace cogeneration plants, the issue is even more complex as it implies reallocating the electricity output between energy players. The same can be expected if the new heat supply implies to prioritize the heat from nuclear plants over renewable or recoverable heat sources. This may be an issue in France given that most DH networks use more than $50 \%$ renewable or recoverable heat sources [66].

\subsubsection{Mankala cluster}

Finnish energy companies follow a unique ownership model, the so-called Mankala principle [67]. Mankala companies are jointly owned by a number of parties that bear the investment and operating costs of the resulting company, and secure an energy supply which corresponds to their share of ownership. Apart from the Mankala model, co-ownership by several utilities has existed in France (e.g. Chooz A, Fessenheim). The organization chart of a Mankala cluster is shown in Figure 3. The nuclear plant and distribution systems would be owned by at least three actors, the nuclear plant operator, the distribution system operator and the end-user. The end-user would then buy heat to the jointly owned company. Whether only the heat output or both the electricity and heat output still to be discussed; it is important to remain open to all the 
possibilities. If the shared ownership applies only to the heat production and distribution (leaving the electricity production to EDF), it would be necessary to rigorously establishing which costs account for electricity production and which costs account for heat production. National authorities could moderate this highly political discussion, possibly providing standardized, long-term contracts.

The main inconvenient of Mankala clusters is the alteration of existing regime boundaries, business models and routines which is required. The advantages are:

- Raising awareness: conducting an institutional innovation through the creation of a public company for joint development of heat distribution systems and nuclear plants could help raising awareness about the existence and potential of such system (as suggested by [68]). This may help avoiding potential electoral barrier, legitimating the financial debts such projects imply.

- End-user participation to decision-making processes: this may make it easier to get support from local authorities, plant owners, NGO and the general public. The end-user(s) could also benefit from advantageous tariffs on the electricity market, adding further economic incentives and legitimacy.

- Risk sharing: the mutualisation of operation and investment costs as well as the creation of an energy managing organization fully empowered by the local authority have been key success factors in the implementation of innovative energy systems, such as the Saclay DH network in France [69]. Bush et al. [41] suggest that business models aiming at sharing the risk (financial but also political or media) among stakeholders are the most appropriate to enhance commitment in collective and exploratory projects.

- Risk reduction: if the government is determined to create a company combining all the necessary skills for the implementation and operation of heat distribution systems and nuclear plants, then transaction costs of the system could decrease significantly. The organisation would also have a larger ability to finance long-term access to capital [68].

- Limited market trade-offs: as the electricity and heat output of the nuclear plant are shared, it would help compensating the market losses that may be feared by the heat distribution actors already in place (especially if operating cogeneration plants; see [14]).

It is well known that collective energy projects are highly marked by power relationships [70,71]. The works on these topics have demonstrated that this power relationship is based precisely on the definition of boundaries. The intermediation in exploratory context consists of blurring existing boundaries by reinventing their definitions (new markets, new constraints understanding, new actor configurations ...), which creates opportunities for "new boundaries" that correspond to possible common interests $[47,56]$. New combinations of partnerships can have a key role in sustainability transitions as they have the potential to challenge incumbent companies and dominant regime practices, ultimately leading to a cultural shift in public and practitioner perceptions of the technology [45]. French intermediaries should focus on stimulating discussions on suitable actor configurations, providing permanent place for the open exchange of ideas and debates.

\section{Conclusion and policy implications}

Recovering the wasted heat from thermal plants, either nuclear or not, is a matter of energy efficiency and should be seen as such. Nuclear plants could remain used for several decades in France, and hence it is legitimate to investigate the possible niche nurturing processes which may allow the emergence of a first project. While there are several experiences of nuclear heat production worldwide [14,46], none is located in France, explaining why many French actors consider such systems as exploratory. Besides, it is a collective innovation in the sense that it would require close collaboration between diverse, disconnected stakeholders. Such exploratory and collective innovations often have difficulties breaking through established regimes, business models and routines. Challenges to the experimentation of heat production with French nuclear plants are high. Nonetheless, it does not make such systems less deserving of inquiry. Discussions on the technical development of energy systems mostly investigate successes, leading to a biased narrative about "winners" that blind energy analysts to the multifarious pathways that energy transitions could follow [72].

This paper examines how innovation intermediaries could interact with other important actors identified by the MLP framework, the niche actors and regime actors, to create niches for nuclear heat production in France. Intermediary actions have been gaining importance as coordination agents facilitating the emergence of innovative energy systems, and this especially in liberalized countries [19]. Well understanding their role is crucial as it may help moving beyond technology-push approaches, which often lead to tension, low legitimacy and credibility $[17,18]$. Those intermediaries that aim to stimulate niche creation for nuclear heat production project (see Tab. 1) could provide permanent domains for the exchange of ideas and drawn upon these exchanges to build-up trustworthy business relationships among a wide variety of actors. Sharing questions instead of knowledge is important at preliminary stages, given that legitimacy is based not on the knowledge itself but on the working conditions surrounding knowledge creation. Such an open cluster could serve as a basis for mobilizing actors through regular meetings or workshops aiming to discuss international experiences of nuclear heat production and to identify suitable location for a first project in France. These meetings should be regularly hold over several years, with significant and clear means (e.g. competence and human capital, financial capital). The objectives should however be defined through iterative and open discussions. More importantly, meetings shall be co-organised and co-animated by intermediaries from diverse sectoral backgrounds (including industrial, heat, nuclear and energy efficiency). Non-governmental organizations, local 
authorities and plant owners should be included in preliminary discussions so as to generate new, sometimes unexpected knowledge, leading to conclusions that can be trusted by everyone. Intermediaries should stimulate discussions on possible actor configurations with the aim to prevent potential resistance to change and split incentives. Conducting an institutional innovation through the creation of a public company jointly owned by the nuclear plant operator, the distribution system operator and the end-user(s) is proposed as a mean to raise awareness about the existence and potential of the system. If the government is determined to create a company that combine all the necessary skills for the implementation of distribution systems and nuclear plants, then transaction costs of the system could decrease significantly. The organisation would have a larger ability to finance longterm access to capital. This could also help avoiding potential electoral barrier, legitimating the debt of the project.

Without significant windows of opportunity (i.e. landscape evolution) however, even the most willing intermediation may not be able to change the status quo. Windows of opportunity could arise externally (e.g. foreign experiences have proved to cost-effectively reduce air pollutants and greenhouse gas emissions; a geopolitical shock has led to the rising up of imported fossil-fuel prices). External events may enhance the political will to consider nuclear heat production, but the opposite is possible (e.g. nuclear incident). Windows of opportunity can also be stimulated internally by intermediaries, through the promotion and dissemination of the potential of nuclear heat production at different geographical scales. The 2012/ $27 /$ EC directive on energy efficiency [73] obligates the facilities emitting a significant amount of excess heat to the surrounding environment to consider DH supply, but explicitly allow the member states to exempt nuclear plants from the duty. In France, precise guidelines are provided to those facilities which must consider whether or not DH supply have cost and climate savings potential [74], but nuclear plants are not targeted. In order to create windows of opportunity for the experimentation of heat production with nuclear plants in France, both the EC and French authorities need to support or at least recognize this alternative. If not, nuclear plant sourced heat will likely remain under valued due to the fact that other heating systems that do not challenge existing regime boundaries would always be prioritized.

Several other evolution of the French regime could also favor the creation of windows of opportunity for the development of innovative, low carbon heating systems, not only nuclear plant sourced. This is however a research topic as itself, and the ideas below should rather be seen as suggestions for future studies that can explore these issues further. The share of renewable or excess heat sources in the total DH deliveries to French networks increased from $7.9 \mathrm{TW}_{\text {th }} / \mathrm{a}$ in 2009 to $13.8 \mathrm{TW}_{\mathrm{th}} / \mathrm{a}$ in 2017 [66]. This leap can be partly attributed to the public DH support set up by the government in 2009 [66]. The 'Fond Chaleur' offers a financial contribution of about $€ 5 / \mathrm{MWh}_{\text {th }}$ to $\mathrm{DH}$ projects aiming to use more than $50 \%$ renewable or excess heat sources, provided that the linear heat density exceeds
1.5 $\mathrm{TWh}_{\text {th }} / \mathrm{m}$.a [75]. However, [75] emphasizes that the number of subsidized DH projects will have to more than double to achieve the French policy objectives. If the development trend of 2009-2017 is prolonged, renewable and excess DH deliveries should total $23 \mathrm{TWh}_{\mathrm{th}} / \mathrm{a}$ in 2030 [75], yet the national objective is $39 \mathrm{TWh}_{\mathrm{th}} / \mathrm{a}$ [76]. A list of the measures designed to enhance faster deployment of low carbon DH schemes is provided in [77]. Alongside, the tax credit scheme supporting the installation of individual, condensing natural gas boilers should be removed considering the large amount of greenhouse gases emitted through natural gas combustion [78] and the demonstrated inefficiency of this mechanism in France [79]. Alteration of the market rules can also take the form of carbon taxation. To that respect, the ambitious carbon price targeted by the 2018 law on finance ( $€ 86.2 / \mathrm{tCO}_{2}$ by 2022 ; [80]) must be recognized for its true value, provided that it is correctly implemented.

In addition to the financial support, national authorities need to provide a clear long-term strategy of where the future energy system is going to go in terms of the energy efficiency levels of buildings and the implications of this for the long-term heat demands upon which DH business cases rest. Clear long-term vision and objectives should also be stated for industrial eco-parks. These visions must be shared across different geographical scales, with precise goals and means. Local authorities know the local geography, context and actors, and hence have the ability to facilitate long-term cooperative projects. The role that they can play in niche nurturing and empowering processes should be strengthened by being further recognized and resourced. The regional authorities also have an important role to play as a facilitator of knowledge sharing and cooperation between the neighbouring local authorities working on similar challenges. Knowledge exchanges across diverse countries and cultures is also a key success factor for unlocking transition to sustainable energy systems. I sincerely hope that this paper can be useful to those researchers which wish to investigate niche nurturing processes of collective and exploratory energy systems holding significant potential for climate change mitigation.

Sincere thanks are given to all the people I had the opportunity to discuss with about the topics at stake in this paper, either from France or Finland, public or private bodies. The great variety of viewpoints, all based on solid arguments, have greatly participated in shaping this paper. I also give warm thanks to Denni Elias and Ruy Sanchez for their support.

\section{References}

1. EC (European Commission), Strategic Energy Technology Plan (SET-Plan), 2015. Available from: http://ec.europa. eu/energy/en/topics/technology-and-innovation/strategicenergy-technology-plan

2. EUROPAIRS, FP7 End User Requirement for Process Heat Applications With Innovative Reactors for Sustainable Energy Supply (EUROPAIRS), 2009. Available from: http://cordis.europa.eu/project/rcn/94416_en.html 
3. IAEA (International Atomic Energy Agency), Desalination Thermodynamic Optimization Program (DE-TOP), 2016. Available from: https://www.iaea.org/NuclearPower/ NEA_Desalination/index.html

4. NC2I, Nuclear Cogeneration Industrial Intiative (NC2i), 2015. Available from: http://www.snetp.eu/nc2i/

5. NEA (Nuclear Energy Agency), Ad hoc Expert Group of the Nuclear Energy Agency on the Role and Economics of Nuclear Co generation in a Low carbon Energy Future (COGEN 2015), 2015. Available from: http://www.oecdnea.org/ndd/groups/cogen.html

6. Ministère de l'environnement, de l'énergie et de la mer (French Ministry of Environment, Energy and Seas), Loi relative à la transition énergétique pour la croissance verte (TECV) (2015) (in French). https://www.legifrance.gouv. fr/affichTexte.do?cidTexte=JORFTEXT000031044385\&ca tegorieLien $=\mathrm{id}$

7. C. Cany, C. Mansilla, P. da Costa, G. Mathonnière, T. Duquesnoy, A. Baschwitz, Nuclear and intermittent renewables: Two compatible supply options? The case of the French power mix, Energy Policy 95, 135 (2016)

8. W.-C. Wang, Techno-economic analysis of a bio-refinery process for producing Hydro-processed Renewable Jet fuel from Jatropha, Renew. Energy 95, 63 (2016)

9. F. Jasserand, J.-G. Lavergne, Initial economic appraisal of nuclear district heating in France, EPJ Nuclear Sci. Technol. 2, 39 (2016)

10. M. Leurent, P. Da Costa, M. Rämä, U. Persson, F. Jasserand, Cost-benefit analysis of district heating systems using heat from nuclear plants in seven European countries, Energy 149, 454 (2018)

11. M. Leurent, P. Da Costa, F. Jasserand, M. Rämä, U. Persson, Cost and climate savings through nuclear district heating in a French urban area, Energy Policy, in press

12. H. Safa, Heat recovery from nuclear power plants, Int. J. Elec. Power Energy Syst. 42, 553 (2012)

13. M. Leurent, P. Da Costa, S. Sylvestre, M. Berthélémy, Feasibility assessment of the use of nuclear plant-sourced steam for French factories considering spatial configuration, J. Clean. Prod. 189, 529 (2018)

14. M. Leurent, F. Jasserand, G. Locatelli, J. Palm, M. Rämä, A. Trianni, Driving forces and obstacles to nuclear cogeneration in Europe: lessons learnt from Finland, Energy Policy 107, 138 (2017)

15. R.E. Bush, C.S.E. Bale, P.G. Taylor, Realising local government visions for developing district heating: experiences from a learning country, Energy Policy 98, 84 (2016)

16. J. Webb, Improvising innovation in UK urban district heating: the convergence of social and environmental agendas in Aberdeen, Energy Policy 78, 265 (2015)

17. J. Barrie, G. Zawdie, E. João, Leveraging triple helix and system intermediaries to enhance effectiveness of protected spaces and strategic niche management for transitioning to circular economy, Int. J. Technol. Manage. Sustain. Dev. 16, 25 (2017)

18. J. Schot, F.W. Geels, Strategic niche management and sustainable innovation journeys: theory, findings, research agenda, and policy, Technol. Anal. Strateg. Manage. 20, 537 (2008)

19. D. Hawkey, J. Webb, Multi-level governance of sociotechnical innovation: the case of district heating in the $\mathrm{UK}$, in Contribution to the Jean Monnet International Workshop, Copenhagen Business School, 2012
20. F.W. Geels, Processes and patterns in transitions and system innovations: refining the co-evolutionary multi-level perspective, Technol. Forecast. Soc. Change 72, 681 (2005)

21. A. Smith, J.-P. Voß, J. Grin, Innovation studies and sustainability transitions: the allure of the multi-level perspective and its challenges, Res. Policy 39, 435 (2010)

22. L.-B. Fischer, J. Newig, Importance of actors and agency in sustainability transitions: a systematic exploration of the literature, Sustainability 8, 476 (2016)

23. P. Kivimaa, F. Kern, Creative destruction or mere niche support? Innovation policy mixes for sustainability transitions, Res. Policy 45, 205 (2016)

24. F. Berkes, H. Ross, Panarchy and community resilience: Sustainability science and policy implications, Environ. Sci. Policy 61, 185 (2016)

25. B. Walrave, M. Talmar, K.S. Podoynitsyna, A.G.L. Romme, G.P.J. Verbong, A multi-level perspective on innovation ecosystems for path-breaking innovation, Technol. Forecast. Soc. Change 136, 103 (2017)

26. M.H. Benson, A.S. Garmestani, Embracing panarchy, building resilience and integrating adaptive management through a rebirth of the National Environmental Policy Act, J. Environ. Manage. 92, 1420 (2011)

27. D. Loorbach, J. Rotmans, The practice of transition management: examples and lessons from four distinct cases, Futures 42, 237 (2010)

28. J.M. Wittmayer, F. Avelino, F. van Steenbergen, D. Loorbach, Actor roles in transition: Insights from sociological perspectives, Environ. Innov. Soc. Transit. 24, 45 (2017)

29. F. Sengers, A.J. Wieczorek, R. Raven, Experimenting for sustain- ability transitions: a systematic literature review, Technol. Forecast. Soc. Change, DOI: 10.1016/j. techfore.2016.08.031

30. S.E. Kalafatis, A. Grace, E. Gibbons, Making climate science accessible in Toledo: the linked boundary chain approach, Clim. Risk Manag. 9, 30 (2015)

31. C. Pahl-Wostl, The role of institutions, actors and social networks in societal change, in Water Governance in the Face of Global Change, Water Governance - Concepts, Methods, and Practice (Springer, Cham, 2015), pp. 51-83

32. T. Gliedt, C.E. Hoicka, N. Jackson, Innovation intermediaries accelerating environmental sustainability transitions, J. Clean. Prod. 174, 1247 (2018)

33. J. Howells, Intermediation and the role of intermediaries in innovation, Res. Policy 35, 715 (2006)

34. J. Mattes, A. Huber, J. Koehrsen, Energy transitions in smallscale regions - what we can learn from a regional innovation systems perspective, Energy Policy 78, 255 (2015)

35. E. Küçüksayraç, D. Keskin, H. Brezet, Intermediaries and innovation support in the design for sustainability field: cases from the Netherlands, Turkey and the United Kingdom, J. Clean. Prod. 101, 38 (2015)

36. C.S. Hayter, A.N. Link, On the economic impact of university proof of concept centers, J. Technol. Transfer 40, 178 (2015)

37. P. Kivimaa, W. Boon, R. Antikainen, Commercialising university inventions for sustainability - a case study of (non-)intermediating "cleantech" at Aalto University, Sci. Public Policy 44, 631 (2017)

38. L. Kompella, E-Governance systems as socio-technical transitions using multi-level perspective with case studies, Technol. Forecast. Soc. Change 123, 80 (2017)

39. L. Levidow, P. Upham, Linking the multi-level perspective with social representations theory: gasifiers as a niche 
innovation reinforcing the energy-from-waste (EfW) regime, Technol. Forecast. Soc. Change 120, 1 (2017)

40. B. van Bree, G.P.J. Verbong, G.J. Kramer, A multi-level perspective on the introduction of hydrogen and batteryelectric vehicles, Technol. Forecast. Soc. Change 77, 529 (2010)

41. R.E. Bush, C.S.E. Bale, M. Powell, A. Gouldson, P.G. Taylor, W.F. Gale, The role of intermediaries in low carbon transitions - Empowering innovations to unlock district heating in the UK, J. Clean. Prod. 148, 137 (2017)

42. A. Kenis, F. Bono, E. Mathijs, Unravelling the (post-) political in transition management: interrogating pathways towards sustainable change, J. Environ. Policy Plann. 18, 568 (2016)

43. F. Kern, Using the multi-level perspective on socio-technical transitions to assess innovation policy, Technol. Forecast. Soc. Change 79, 298 (2012)

44. J.H. Sieg, M.W. Wallin, G. von Krogh, Managerial Challenges in Open Innovation: A Study of Innovation Intermediation in the Chemical Industry (SSRN Scholarly Paper No. ID 1602201), Social Science Research Network, Rochester, NY, 2010

45. L. Klerkx, C. Leeuwis, Balancing multiple interests: Embedding innovation intermediation in the agricultural knowledge infrastructure, Technovation 28, 364 (2008)

46. IAEA (International Atomic Energy Agency), Market Potential for Non-electric Applications of Nuclear Energy, STI/DOC/010/410, 2003

47. M. Agogué, E. Berthet, T. Fredberg, P.L. Masson, B. Segrestin, M. Stoetzel, M. Wiener, A. Yström, Explicating the role of innovation intermediaries in the "unknown": a contingency approach, J. Strateg. Manag. 10, 19 (2017)

48. T. Inkinen, K. Suorsa, Intermediaries in regional innovation systems: high-technology enterprise survey from Northern Finland, Eur. Plan. Stud. 18, 169 (2010)

49. A. Bergek, S. Jacobsson, B. Carlsson, S. Lindmark, A. Rickne, Analyzing the functional dynamics of technological innovation systems: a scheme of analysis, Res. Policy 37, 407 (2008)

50. M.P. Hekkert, R.A.A. Suurs, S.O. Negro, S. Kuhlmann, R.E.H.M. Smits, Functions of innovation systems: A new approach for analysing technological change, Technol. Forecast. Soc. Change 74, 413 (2007)

51. H. van Lente, M. Hekkert, R. Smits, B. van Waveren, Roles of systemic intermediaries in transition processes, Int. J. Innov. Manag. 07, 247 (2003)

52. A. Hatchuel, P.L. Masson, B. Weil, Teaching innovative design reasoning: how concept-knowledge theory can help overcome fixation effects, Artif. Intell. Eng. Des. Anal. Manuf. 25, 77 (2011)

53. S.E. Fawcett, S.L. Jones, A.M. Fawcett, Supply chain trust: the catalyst for collaborative innovation, Bus. Horiz. 55, 163 (2012)

54. F. Geels, R. Raven, Non-linearity and expectations in nichedevelopment trajectories: ups and downs in Dutch biogas development (1973-2003), Technol. Anal. Strateg. Manag. 18, 375 (2006)

55. M. Hodson, S. Marvin, Can cities shape socio-technical transitions and how would we know if they were? Res. Policy 39, 477 (2010)

56. K. Matschoss, E. Heiskanen, Making it experimental in several ways: the work of intermediaries in raising the ambition level in local climate initiatives, J. Clean. Prod. 169, 85 (2017)
57. J. Klewitz, A. Zeyen, E.G. Hansen, Intermediaries driving eco-innovation in SMEs: a qualitative investigation, Eur. J. Innov. Manag. 15, 442 (2012)

58. NC2I, Experience Feedback from Nuclear Cogeneration. Contribution of C. Auriault, M.A. Fütterer, O. Baudrand to the NC2I Conference, CDMA Brussels, 2015

59. Decentralized energy, Chinese firm to develop nuclear district heating plant (2017). http://www.decentralizedenergy.com/articles/2017/12/chinese-firm-to-develop-nucle ar-district-heating-plant.html

60. M. Leurent, P. Da Costa, S. Sylvestre, M. Berthélémy, Feasibility assessment of the use of nuclear plant-sourced steam for French factories, taking spatial configuration into consideration, J. Clean. Prod. 189, 529 (2018)

61. J. Sanderson, Risk, uncertainty and governance in megaprojects: a critical discussion of alternative explanations, Int. J. Proj. Manag. 30, 432 (2012)

62. A. Dalmasso, Le projet Thermos (1975-1981) ou l'échec de l'atome au coin du feu, Colloque Nucléaire et développement régional, Tours, CEHMVI, Fondation EDF, 17-18 Décembre, 2008 (in French)

63. NEA (Nuclear Energy Agency), On the Role and Economics of Nuclear Cogeneration in a Low Carbon Energy Future, 2018 , in press

64. P. Hirsch, K. Duzinkiewicz, M. Grochowski, R. Piotrowski, Two-phase optimizing approach to design assessments of long distance heat transportation for CHP systems, Appl. Energy 182, 164 (2016)

65. G. Locatelli, S. Boarin, F. Pellegrino, M.E. Ricotti, Load following with small modular reactors (SMR): a real options analysis, Energy 80, 41 (2015)

66. SNCU (French National Union for District Heating), Enquête annuelle sur les réseaux de chaleur et de froid. Rapport 2017. Edition nationale (2017) (in French). http://www.sncu. fr /Actualite-Agenda/Actualites /Enquete-nationale-sur-lesreseaux-de-chaleur-et-de-froid-Edition-2017-Chiffres-2016

67. I. Puikkonen, Cooperative Mankala-Companies - the acceptability of the company form in EC competition law, Helsinki Law Rev. 1, 139 (2010)

68. A. Colmenar-Santos, E. Rosales-Asensio, D. Borge-Diez, F. Mur-Pérez, Cogeneration and district heating networks: measures to remove institutional and financial barriers that restrict their joint use in the EU-28, Energy 85, 403 (2015)

69. EC (European Commission), Efficient district heating and cooling systems in the EU. Case studies analysis, replicable key success factors and potential policy implications, 2016. http://publications.jrc.ec.europa.eu/repository/bitstream/ JRC104437/study\%20on\%20efficient\%20dhc\%20systems\% 20 in $\% 20$ the $\% 20$ eu $\% 20$-dec2016 final\%20-\%20public\%20re port6.pdf

70. F.M. Santos, K.M. Eisenhardt, Constructing markets and shaping boundaries: entrepreneurial power in Nascent fields, Acad. Manage. J. 52, 643 (2009)

71. B.K. Sovacool, C.J. Cooper, The Governance of Energy Megaprojects: Politics, Hubris and Energy Security (Edward Elgar, Cheltenham, 2013)

72. B.K. Sovacool, What are we doing here? Analyzing fifteen years of energy scholarship and proposing a social science research agenda, Energy Res. Soc. Sci. 1, 1 (2014)

73. European Parliament, Directive 2012/27/EU of the European Parliament and of the Council of 25 October 2012 on energy efficiency, amending Directives 2009/125/EC and 2010/30/EU and repealing Directives 2004/8/EC and 2006/32/EC, 2012 
74. Ministère de l'écologie, du développement durable et de l'énergie (French Ministry of Ecology, Sustainable development and Energy), 2014. Ministère de l\#XPS\#rsquo; écologie, du développement durable et de l'énergie, 2014. Application de l'article 14.5 de la directive 202/27/EU sur la valorisation de la chaleur fatale industrielle via des réseaux de chaleur. Décret n 2014-1363 du 14 Novembre, 2014

75. ADEME (French Agency for Environment and Energy Supervision), 13ième Rencontres des réseaux de chaleur (13th National DH Meeting), Round Table of the 12/12, Presentation by Rémi Chabrillat "Factor 5 for renewable and excess heat sources: Which means for which objectives?", 2017 (in French)

76. Assemblée Nationale (French national assembly), Loi n ${ }^{\circ} 2015-$ 992 du17 aoÛt 2015 Relative à la transition énergétique pour la croissance verte, 2015-2992 (2015). http://www.legifrance.
gouv.fr/affichTexte.do?cidTexte $\frac{1}{4} J O R F T E X T 000031044385 \&$ categorieLien $\frac{1}{4}$ id

77. AMORCE (French district heating association), 9 propositions du comité national des acteurs des réseaux de chaleur (2017) (in French). http://www.amorce.asso.fr/fr/espaceadherents / publications / rdc/parties-prenantes / 9-proposi tions-du-comite-national-des-acteurs-des-reseaux-de-chaleur/

78. IPCC (Intergovernmental Panel on Climate Change), Guidelines for National Greenhouse Gas Inventories, Energy (2006), Vol. 2

79. D. Charlier, Energy efficiency investments in the context of split incentives among French households, Energy Policy 87, 465 (2015)

80. Assemblée Nationale, LOI n 2017-1837 du 30 décembre 2017 de finances pour 2018 (2017) (in French). https://www.legifrance. gouv.fr/eli/loi/2017/12/30/CPAX1723900L/jo/texte/\#

Cite this article as: Martin Leurent, Stimulating niche nurturing process for heat production with nuclear plants in France: A multi-level perspective, EPJ Nuclear Sci. Technol. 5, 5 (2019) 